Acta Cryst. (1993). C49, 424

\section{Access to CIFs archived in Chester}

Since 1 January 1992 all structural papers submitted for publication in Sections B and C of Acta Crystallographica have had their numerical content checked in Chester and there is an associated CIF for each paper.

The CIF will contain either (i) numerical information and the whole of the text of the paper if the submission was made electronically in CIF format or (ii) numerical information, the Experimental Section and some of the text if the CIF was generated in Chester from a hard-copy submission.
The CIF for each paper is uniquely identified by the CIF reference number which appears in the deposition footnote; this reference number is used as the basis for storing the file in the archive directory.

An email file server is installed in the Chester office and readers who are interested in retrieving CIFs via email and who are subscribers to (or whose libraries or institutions are subscribers to) Section C of Acta Crystallographica (or Section B as appropriate) are invited to contact the Technical Editor (International Union of Crystallography, 5 Abbey Square, Chester $\mathrm{CH} 1$ 2HU, England; teched@iucr.ac.uk) who will supply details on the use of the email file server. CIFs can also be supplied on diskette, if preferred.

This service is provided on an experimental basis and there is no charge. 